\section{Breaking the bottle neck to enhance pediatrics renal transplantation at Soba university hospital: Role of a non-governmental organization}

\author{
Ihab B. Abdalrahman, ${ }^{1}$ \\ Shaima N. Elgenaid, ${ }^{2}$ Rashid Ellidir, ${ }^{3}$ \\ Asma Nizar Mohammed Osman \\ Abdallah, ${ }^{4}$ Safa Ahmed Hassan Hamid, ${ }^{4}$ \\ Shahd H. A. Elwidaa, ${ }^{2}$ \\ El-Tigani M. A. Ali ${ }^{5}$ \\ ${ }^{1}$ Faculty of Medicine, University of \\ Khartoum, Soba University Hospital, \\ Khartoum; ${ }^{2}$ Department of Internal \\ Medicine, Faculty of Medicine, \\ University of Khartoum, Khartoum; \\ ${ }^{3}$ Department of Pediatric Nephrology, \\ Soba University Hospital, EInelien \\ University; ${ }^{4}$ Soba Center for Audit and \\ Research, Faculty of Medicine, \\ University of Khartoum, Khartoum; \\ ${ }^{5}$ Pediatric Nephrology Unit, Soba \\ University Hospital, Khartoum, Sudan
}

\begin{abstract}
High cost and limited resources of pediatrics renal transplant in low-resource countries limits the number of transplants. However, the collaboration between government and community sector provided high quality care for these patients. Here we highlight the impact of a non-governmental organization in facilitating pediatrics renal transplant. Data was collected from files of all pediatric patients withend stage renal disease who received renal transplant between January 2010 and December 2017 at Soba University Hospital (77 patients). The 8-year period was divided into 16 intervals of 6 months each. The number of patients who received renal transplant ranged from 1 to 12 patients in each interval. There was a rise in 2017 when 21 (28.7\%) patients received kidney transplant. In the last 6 months in 2017 there was a significant reduction in duration of hospital stay compared to the rest of the period; it dropped from 16.36 to 9.92 days $(\mathrm{P}=0.003)$. Partnership between governmental and non-governmental sectors is a good strategy in low resource area to bridge some of the gaps of healthcare delivery system.
\end{abstract}

\section{Introduction}

The prevalence of renal replacement therapy in children under 19 years of age is
18-100 per million of age related population. ${ }^{1}$ The first successful renal transplant was done in 1945 and since then it has been considered the treatment of choice for patients with end stage renal disease. ${ }^{2}$ The long-term cost of renal transplant is less than that of the dialysis, particularly when the duration of the therapy is more than 16 months. The estimated cost of conventional dialysis at 40 months is more than 87,000 USD in compare to only 48,000 USD for transplant in 50 months. ${ }^{3}$ The cost of renal transplant in Sudan was equivalent to 10 months of hemodialysis.

In developing countries, the prevalence of children kidney transplantation is less than 5 patients per million, due to low resources and minimal support by the governments. The high cost and far distance of specialized center contributes to limited number of transplants. For the same previous reasons, the mortality rate due to end stage renal disease (ESRD)in low-resource area is high. Even those who received transplant cannot maintain their graft due to high cost of post-transplant medication, and in case of rejection only $2 \%$ of patients could pay for second graft but no more., ${ }^{4,5}$ Involvement of non-governmental sector in supporting renal transplantation to a level of cost-free service, led to an increase in the number of patients undergoing transplantation and made it more socially acceptable. ${ }^{4}$ In Pakistan, the high cost of renal replacement therapy deprived more than $90 \%$ of ESRD patients from undergoing treatment, ${ }^{6}$ but the collaboration between government and community sector led to availability of free and high quality care for those patients. ${ }^{7}$

In health sector, Non-Governmental organizations (NGOs) target specific health problem and deliver comprehensive services to manage it. A NGO delivers health services to vulnerable patients who cannot handle the cost of health care. ${ }^{8}$ The efficiency of NGOs in bridging service-delivery gaps, rely on knowledge, proficiency, ability of these institute to tackle and focus on health needs in the community that not covered by the government. ${ }^{9}$ In north Darfur state, Sudan, international NGOs provide about $70 \%$ of health services through training of healthcare staff, funding and establishment of new health centers. ${ }^{10}$

Sadaqaat Charity Organization (SCO) is non-profit, non-political, charity organization. It was established as an initiative in 2002 by Sudanese graduates doing their postgraduate training in USA. In 2012 it was registered officially in the Humanitarian Affairs Commission in Sudan. The vision of the organization is to promote the efficiency of social services in
Correspondence: Shaima N. Elgenaid, Department of Internal Medicine, Faculty of Medicine, University of Khartoum, Khartoum, Sudan.

E-mail: Shema2690@gmail.com

Key words: Non-governmental organization; Pediatrics; Renal transplantation; Lowresource; Sadagaat Charity Organization.

Contributions: IBA designed the study, interpreted data, managed literature search and wrote the first draft of the manuscript; SNE performed data analysis, interpreted data, managed literature search and wrote first draft of the manuscript; RE performed data collection and wrote first draft of the manuscript; ANMOA, SAHH, SHAE performed data analysis and interpretation; ETMAA and all other authors read and approved the final version to be published.

Received for publication: 10 November 2018. Revision received: 14 July 2019.

Accepted for publication: 25 September 2019.

This work is licensed under a Creative Commons Attribution 4.0 License (by-nc 4.0)

(Copyright: the Author(s), 2019

Licensee PAGEPress, Italy

Healthcare in Low-resource Settings 2019; 7:7930

doi:10.4081/hls.2019.7930

Sudan. SCO works in 4 domains: i) provision of clean water in hardship areas, ii) food service for the needy, iii) improving general education and iv) improving health service. In health, SCO works in improving the health delivery environment by rehabilitating or establishing facilities and provision of needed equipment and supplies; capacity building by training health workers in both knowledge and skills; awareness programs like voluntary blood donation and screening for breast cancer among women. In children with renal failure, SCO provides free dialysis catheters and other consumables and some of the long-term medications. Free transportation to treatment facilities is also provided to needy families. Some of Sadagaats' volunteers tutor these children during their dialysis session so as not to miss academic development.

Soba University Hospital is the only pediatrics renal transplantation center in Sudan. The first pediatrics renal transplant was done in May 2010. The facility has only 2 beds of high dependency unit (HDU) dedicated for pediatrics renal transplant. Many of the transplant recipients were coming from rural areas and they had no place to stay in the city. This led to prolonged hospital stay and blocking the hospital beds. 
Once hospital stay was protracted, Sadagaat was requested by renal transplant team to help the families by renting apartment close to the hospitals. This used to occur sporadically. After a brain storming session between transplant team and SCO leaders, Sadagaat leadership were convinced to provide 4 apartments on continuous basis to facilitate early discharge of stable patient. This was thought to improve accessibility of the HDU beds and probably shorten the waiting list. To ensure safety and coordination of medical care, Sadagaat hired a registered nurse from the transplant team as a part timer to supervise these children and facilitate early and easy transfer to the hospital whenever it was needed. In this report we are exploring the impact of these simple interventions.

\section{Materials and Methods}

This is retrospective study was conducted in January 2018 to determine the role of NGO in improving health care delivery in low resource area. Our inclusion criteria were all pediatric patients with ESRD who received renal transplant at Soba University hospital (Khartoum) and post-transplant care between January 2010 and December 2017. We selected all patients because of limited number of patients. Data was collected from patients' files in the hospital, which included demographic data, duration of dialysis, duration till discharge and some of post-transplant complications. Data was analyzed using Excel software and SPSS statistics 22. We divided the mentioned period (from January 2010 to December 2017) into intervals, each of 6 months. The number of patients who underwent renal transplant surgery was determined in each interval along with mean duration of dialysis, mean days till discharge and number of patients who developed post-transplant complications in each interval. We did a comparison using independent $t$ test between these variables in (January 2010June 2017) and (July 2017-December 2017). P-value of 0.05 was considered statistically significant. The proposal of this study was approved by Soba Center for Audit and Research. Consent was waived.

\section{Results}

Data was collected from 77 pediatric patients with ESRD who received renal transplant at Soba hospital in Khartoum from January 2010 to December 2017. Females and males were $43(56 \%)$ and 34 (44\%) respectively. Their age ranged from 8 to 18 years with mean age for male and female of 13.59 year and 13.81 year respectively. The graft for all patients came from related living donor, a significant proportion of $45.9 \%$ received allograft from their mothers while the rest received kidney from their fathers, brothers and sisters. The 8 years period was divided into 16 intervals with 6 months in each. The number of patients in each interval is shown in Table 1.

The number of patients who received renal transplant in each six-month interval between January 2010 and December 2016 ranged from 1 to 6 patients. There was a considerable rise in the number of patients in 2017 with $9(12.3 \%)$ patients and 12 (16.1\%) patients who received kidney transplant in the first and second half respectively. Moreover, the number of transplants in the entire $2017(21(28.7 \%))$ represents the highest rate of transplant in compare to the previous years. This coincided with the facilitation of early discharge to residential apartment, thus improving accessibility of the HDU beds and probably shortening the waiting list. This was associated with sig- nificant reduction in duration of hospital stay as it dropped from 16.36 to 9.92 days $(\mathrm{P}=0.003)$ as shown in Table 2.

\section{Discussion}

In developing countries, scarcity of resources is major determinant of service availability and sustainability. In this report we are reflecting on role of NGO in improving health care delivery in low-resource area. SCO participated actively by providing medication and supplies to improve health care for renal transplant patients since the invention of this service. In Sudan, out of all patients with end stage renal failure, only $3.9 \%$ had received transplant while about two third received either chronic hemodialysis or had intermittent peritoneal dialysis. ${ }^{11}$

Creation of supervised residential home in 2017 helped to increase the number of patients who had renal transplant by $75 \%$ compared to 2016. In Pakistan, the collabo-

Table 1. Number of patients who received renal transplant in the period between January 2010 and December 2017, and post-transplant complications.

\begin{tabular}{lccc} 
Date & Number of patients & DVI & Death \\
Jan-Jun 2010 & $1(1.4 \%)$ & 0 & 0 \\
Jul-Dec 2010 & $2(2.7 \%)$ & 0 & 0 \\
\hline Jan-Jun 2011 & $4(5.5 \%)$ & 0 & 0 \\
Jul-Dec 2011 & $3(4.1 \%)$ & 0 & 0 \\
\hline Jan-Jun 2012 & $4(5.5 \%)$ & 0 & 0 \\
Jul-Dec 2012 & $3(4.1 \%)$ & 0 & 0 \\
\hline Jan-Jun 2013 & $3(4.1 \%)$ & 2 & 0 \\
Jul-Dec 2013 & $2(2.7 \%)$ & 0 & 2 \\
\hline Jan-Jun 2014 & $3(4.1 \%)$ & 0 & 0 \\
Jul-Dec 2014 & $6(8.2 \%)$ & 0 & 0 \\
\hline Jan-Jun 2015 & $5(6.8 \%)$ & 0 & 0 \\
Jul-Dec 2015 & $4(5.5 \%)$ & 0 & 0 \\
\hline Jan-Jun 2016 & $6(8.2 \%)$ & 0 & 0 \\
Jul-Dec 2016 & $6(8.2 \%)$ & 0 & 0 \\
\hline Jan-Jun 2017 & $9(12.3 \%)$ & 0 & 0 \\
Jul-Dec 2017 & $12(16.4 \%)$ & 1 & 2 \\
\hline Total & $73(100 \%)$ & 3 &
\end{tabular}

DVT, deep vein thrombosis.

Table 2. The difference between January 2010-June 2017 and July 2017-December 2017.

\begin{tabular}{lccc} 
Item & Jan 2010-Jun 2017 & Jul 2017-Dec 2017 & P-value \\
Mean duration of dialysis (month) & 22.8 & 15.08 & 0.270 \\
Mean days till discharge & 16.36 & 9.92 & 0.003 \\
\hline Haemorrhage & $6(10.2 \%)$ & $2(16.7 \%)$ & 0.72 \\
Wound infection & $6(10.2 \%)$ & $1(8.3 \%)$ & 0.92 \\
\hline DVT & $2(3.4 \%)$ & $1(8.3 \%)$ & 0.837 \\
Infections (viral, bacterial) & $13(21.7 \%)$ & $0(0 \%)$ & 0.4 \\
\hline
\end{tabular}

DVT, deep vein thrombosis. 
ration between government and community sector led to availability of free and high quality care for renal patients. ${ }^{7}$ Similarly in study done in Pakistan by Rizvi et al., the cooperation between government and community organizations in providing free dialysis and renal transplantation led to increase in the number of dialysis and transplant patients from 380 and 103 in 1999 to 1350 and 544 in 2009, respectively. ${ }^{12}$ It seems that NOGs interventions are effective in bridging some of gaps in developing countries. The partnership between private and public sectors is needed for better healthcare services delivery regarding renal transplantation. ${ }^{13}$ In this report, the transplant team faced bottle-necks repeatedly. This was related to blockage of post-transplant renal beds by patients who developed some complications or required longer observation. Another factor was the inability to discharge some patients who has no accommodation in the city. Sadagaat's intervention is not a new concept in health delivery. This represents implementation of other countries experience in a local context. To make the idea acceptable and matching the local context SCO rented 4 apartments, each with 2 rooms, electricity, water and cleaning services. Each room was dedicated to one family (transplant recipient and one family member). This has increased the number of renal transplants in children without significant complications and might also helped in reducing the risk of acquiring health care associated infection. Creation of home like environment might have had a positive psychological impact of the wellbeing of the patients and their families. Non-governmental organization support of renal transplant is a recognized measure that have potential impact on provision of renal replacement therapy for larger number of patients in need, along with other measures such as development of local transplant program and use of local manufactured drugs and dialysis. ${ }^{14}$

Utilization of nurses or health care aid to deliver professional home care is well known method in many countries. ${ }^{15}$ This helped to reduce the cost of escalating medical care in acute care facilities. ${ }^{16}$ This model of care is used sporadically in Sudan by some medical professional in collaboration with family members. SCO utilized this concept of supervised care in the residential home. This created the opportunity to recognize the medical needs of the residents coupled with professional ability to access and coordinate immediate care at the hospital. Having a professional from the transplant team was based on the assumption that having such a nurse will help to build relation and generate trust between the nurse and the family. Interestingly early discharge from hospital with supervised home care was not associated with significant adverse outcomes. Having a nurse from the same facility might have partially addressed the concern regarding system design. ${ }^{17}$ These simple measures led to an improvement in the flow of transplantations and significant reduction in hospital stay from 16.36 to 9.92 days $(\mathrm{P}=0.003)$ when comparing the last six months in 2017 and the rest of the period. This almost matched the number of hospitalization days in other countries. ${ }^{18}$ A study by Hushie revealed that Partnership between government and community organization can improve service delivery and insure equity to all people in the targeted population.

NGOs play an important role in health care support in developing country. Transplant links community organization in UK conducted 10 years project in low resource country in Africa regarding renal transplant in adult and pediatric through continuous visit, skill transfer and monitoring of transplantation unit. They found that all those monitored by the program have made significant improvement toward sustainability but it can only be achieved when continuous financial support is also available. ${ }^{19}$ Most of such studies regarding the effect of NGO in renal transplantation were conducted in middle-low income countries.

\section{Conclusions}

Simple interventions by NGOs are reasonable solutions to bridge some of gaps and solve some of health delivery problems. Partnership between governmental and nongovernmental sector is a good strategic method in low-resource area

\section{References}

1. Harambat J, Van Stralen KJ, Kim JJ, Tizard EJ. Epidemiology of chronic kidney disease in children. Pediatr Nephrol 2012;27:363-73.

2. Offner G, Latta K, Hoyer PF, et al. Kidney transplanted children come of age. Kidney Int 1999;55:1509-17.

3. de Camargo MFC, de Souza Barbosa K, Fetter SK, et al. Cost analysis of substitutive renal therapies in children. J Ped 2018;94:93-9.

4. Rizvi S, Sultan S, Zafar M, et al. Pediatric kidney transplantation in the developing world: challenges and solutions. Am J Transplant 2013;13:2441-9.

5. Verma B, Bhandari M, Kumar A, eds. Transplantation in developing countries: economics, reality, and solutions. Transplantation proceedings. Elsevier; 2000.

6. Rizvi AHS, Naqvi AS, Zafar NM, Ahmed E. Regulated compensated donation in Pakistan and Iran. Curr Opinion Organ Transplant 2009;14:124-8.

7. Rizvi SAH, Naqvi SAA, Zafar MN, Akhtar SF. A kidney transplantation model in a low-resource country: an experience from Pakistan. Kidney Int Suppl 2013;3:236-40.

8. Gilson L, Sen PD, Mohammed S, Mujinja P. The potential of health sector non-governmental organizations: policy options. Health Policy Plann 1994;9:14-24.

9. Hushie M. Public-non-governmental organisation partnerships for health: an exploratory study with case studies from recent Ghanaian experience. BMC Public Health 2016;16:963.

10. Yagub AI, Mtshali K. The role of nongovernmental organizations in providing curative health services in North Darfur State, Sudan. Afr Health Sci 2015;15: 1049-55.

11. Ali E-TM, Abdelraheem MB, Mohamed $\mathrm{RM}$, et al. Chronic renal failure in Sudanese children: aetiology and outcomes. Pediatr Nephrol 2009;24:349-53.

12. Rizvi S, Naqvi S, Zafar M, et al. A renal transplantation model for developing countries. Am J Transplant 2011;11:23027.

13. Akoh JA. Renal transplantation in developing countries. Saudi J Kidney Dis Transplant 2011;22:637.

14. White SL, Chadban SJ, Jan S, et al. How can we achieve global equity in provision of renal replacement therapy? Bull World Health Organ 2008;86:229-37.

15. Chappell NL, Hollander MJ. An evidence-based policy prescription for an aging population. Healthcare Pap 2011; 11:8-18.

16. Boris E, Klein J. Organizing home care: low-waged workers in the welfare state. Polit Soc 2006;34:81-108.

17. Storch J, Curry C, Stevenson L, et al. Ethics and safety in home care: perspectives on home support workers. Nurs Leadersh (Tor Ont) 2014;27:76-96.

18. NAPRTCS. 2014 Annual Transplant Report. NAPRTCS; 2014. Available from: https://web.emmes.com/study/ ped/annlrept/annualrept2014.pdf.

19. Ready AR, Nath J, Milford DV, et al. Establishing sustainable kidney transplantation programs in developing world countries: a 10-year experience. Kidney Int 2016;90:916-20. 